\title{
A 90-Day Oral Toxicity Study of the Ethanol Extract from Eupatorium japonicum Thunb and Foeniculum vulgare in Rats
}

\author{
Guangcheng Dai, ${ }^{1}$ Chenglu Wang, ${ }^{2}$ Wei Tang, ${ }^{1}$ Jiangyun Liu, ${ }^{3}$ and Boxin Xue ${ }^{1}{ }^{1}$ \\ ${ }^{1}$ Department of Urology, The Second Affiliated Hospital of Soochow University, Suzhou 215004, China \\ ${ }^{2}$ Department of Reproductive Endocrinology, Zhejiang Provincial People's Hospital, Hangzhou Medical College, \\ Hangzhou 310014, China \\ ${ }^{3}$ College of Pharmaceutical Sciences, Soochow University, Suzhou 215123, China
}

Correspondence should be addressed to Boxin Xue; xbxurol@163.com

Received 12 March 2020; Revised 7 June 2020; Accepted 19 June 2020; Published 27 June 2020

Academic Editor: Stefano Curcio

Copyright (c) 2020 Guangcheng Dai et al. This is an open access article distributed under the Creative Commons Attribution License, which permits unrestricted use, distribution, and reproduction in any medium, provided the original work is properly cited.

\begin{abstract}
Eupatorium japonicum Thunb and Foeniculum vulgare are two of the most widely used folk herbs and constituents in many traditional Chinese herbal formulas. Nonetheless, little toxicological and safety information associated with following daily repeated exposure is obtained according to previous research. The present study was performed to assess the toxicity of ethanol extract from Eupatorium japonicum Thunb and Foeniculum vulgare (EFE) in male rats administered by dietary oral gavage at target doses of $0.39,0.78$, and $1.56 \mathrm{~g} / \mathrm{kg}$ body weight/day for 90 days. There were no significant adverse effects on clinical signs, body weight, food conversion efficiency, and vital hematological indices. However, some hematology and biochemical indices such as WCV, MCH, MCHC, LY, MPV, T-CHO, as well as TG revealed significant changes in Sprague-Dawley rats and organ weights in lung and spleen showed diminished in male rats. Necropsy and histopathology findings suggested that no significant differences in absolute weights were found in all organs except lung and spleen, and no treatment-related alteration was identified in any organs. All results obtained in the present study indicated that the proper use of EFE in traditional medicine at oral dosages up to $1.56 \mathrm{~g} / \mathrm{kg} /$ day body weight may harbor no prolonged toxicity to rats. However, further studies of EFE are still necessary to assess its oral safety in patients.
\end{abstract}

\section{Introduction}

Eupatorium japonicum Thunb and Foeniculum vulgare are widely used by folk and traditional medicines in many ancient Chinese herbal formulas. Eupatorium japonicum Thunb, belonged to the family of Asteraceae in the Asterales within the Angiosperms, is widespread in China, Japan, and Korea. According to previous researches, the leaves and stems have been shown the effect of anti-inflammatory and vascular smooth muscle relaxant (1). Therefore, Eupatorium japonicum Thunb are identified as the effective antivirals, antibacterials, diuretics, painkillers, vermifuges, and carminatives (2). And it is utilized for the treatment of vomiting, indigestion, nausea, and diarrhea (The Chinese People's Pharmacopoeia, 2005) (3). Foeniculum vulgare, the oldest valid name within the genus Foeniculum, is a flowering plant species widely cultivated in almost all countries of the world (4). It is an ancient and popular herb with a long utilization history. Several past studies have shown that numerous infections disorders including bacterium, fungus, virus, and mycobacterium can be effectively controlled using Foeniculum vulgare (5-7). It has been suggested that Foeniculum vulgare has multiple biological functions such as cytoprotective, hypoglycemic, chemopreventive, hepatoprotective, and oestrogenic activities according to previous literature (8-12). Recently, some researchers stated that Foeniculum vulgare can be used for management stress-related disorders because of its antistress and memory-enhancing function (13).

In our previous study, Ethanol extract from Eupatorium japonicum Thunb and Foeniculum vulgare (EFE) can regulate the balance of sex hormone and decrease the hyperplasia epithelia of prostate in male Sprague-Dawley (SD) rats, 
which might result in an inhibitory effect of benign prostatic hyperplasia (14). Nonetheless, to our knowledge, no data are available so far on the safety assessment of EFE in animals. Therefore, the present research investigated the potential toxicity of EFE using a 90-day feeding study in male SD rats.

\section{Materials and Methods}

\subsection{Materials}

2.1.1. Preparation of EFE. The whole plants of Eupatorium japonicum Thunb and Foeniculum vulgare were purchased from the local Chinese herb market and the voucher specimens were deposited in the herbarium of College of Pharmaceutical Sciences, Soochow University (Suzhou, China).

For the ethanol extract preparation, formula herbs $20 \mathrm{~kg}$ (Eupatorium japonicum Thunb. and Foeniculum vulgare were marked, respectively, $1: 1$ ), dried and teared for preparation, reflux extraction twice with 10 times $85 \%$ ethanol, 1.5 hours every time, merge extracting solution, decompression enrichment to a quarter of the volume and let stand for the night, precipitation with Buchner funnel, filtration solution concentration under vacuum to the density of 1.05 in the temp of $60^{\circ} \mathrm{C}$, the ethanol solution is concentrated by reducing pressure and dried by vacuum; finally, $1.56 \mathrm{~kg}$ block solid extract is obtained, which was utilized in the following tests. The yield of EFE was $7.8 \%$.

2.2. Experimental Animals. Forty male adult Sprague-Dawley rats, 6 weeks old, 124.5-142.0 g, were purchased from the Slac Laboratory Animal Co., Ltd. (Shanghai, China). Mice were individually kept in cages with stainless steel grid covers, bedded with sterilized wood shavings, and were cared in a controlled environment. The commercial diets (Suzhou Shuangshi Laboratory Animal Feed Science and Technology Co., Ltd. Soochow) and tap water were provided ad libitum. The rats were allowed 1 week for acclimation prior to the conduction of experiments.

All animals received human care according to the Chinese legislation on the usage and care of laboratory animals. The study was approved by the committee of Soochow University of Science and Technology.

2.3. Study Design Overview. The study was performed based on the Procedure and Methods of Food Safety Toxicological Assessment, GB15193.13-2003 (in Chinese) (15).

2.3.1. 90-Day Period of Feeding Study. After getting 7-day periods of acclimatization, forty rats were used in the study. The dose was discussed according to the results of previous and pharmacodynamic and acute oral toxicity study. All rats were randomly selected and included into three treatment groups and a control group. The oral feeding was continually conducted (i. g.) at the same time from Monday to Saturday each week, during the 90 -day period for EFE-1 $(0.39 \mathrm{~g} / \mathrm{kg} /$ day $)$, EFE-2 $(0.78 \mathrm{~g} / \mathrm{kg} /$ day $)$, EFE-3 $(1.56 \mathrm{~g} / \mathrm{kg} /$ day $)$, and control (water, $10 \mathrm{ml} / \mathrm{kg} /$ day) groups (14).

Signs of toxicity and mortality were observed throughout the experimental period. All rats were weighed at the beginning of the administration, then recorded every four days during the experimental period and at the end of the study. Also, food consumption was calculated every four days, and total food consumption for each rat was assessed by summation of the food intake recorded from every feeding period. Furthermore, food conversion efficiency was measured as the weight gain per gram of food consumed.

At the end of the 90-day oral feeding, rats were sacrificed after diets withdrawing $16 \mathrm{~h}$. Blood from abdominal aorta were collected and divided into two tubes for blood hematological and chemistry analysis, respectively. We then weighed and performed histopathological examinations on organs such as heart, spleen, lung, liver, kidney, brain, thymus, adrenal gland, testes, and epididymis.

\subsection{Observations}

2.4.1. Clinical Signs. We continuously monitored the changes every day in physical appearance, behavioral pattern, breath, glandular secretion, excreta, mortality, and signs of illness throughout the experiment. Additionally, the body weight of each rat was observed every four days in our oral toxicity study.

\subsubsection{Body Weight, Food Consumption, and Food Conversion} Efficiency. Body weight was recorded on the first day of administration, then recorded every four days during the 90-day feeding and at the end of the experiment. Food consumption was evaluated over successive periods of 90 days by weighing the rats. In addition, food conversion efficiency was measured as the weight gain per gram of food consumed.

2.4.3. Hematological and Biochemical Analyses. Hematological parameters, including white blood cell (WBC), red blood cell (RBC), hemoglobin ( $\mathrm{Hb})$, five-classification of WBC (Neutrophil, NE/Lymphocyte, LY/Eosinophil, EO/Monocyte, $\mathrm{MO} /$ Basophil, BA), hematocrit (HCT), mean corpuscular hemoglobin $(\mathrm{MCH})$, mean corpuscular volume (MCV), mean corpuscular hemoglobin concentration (MCHC), mean platelet volume (MPV), and red cell distribution width-coefficient of variation (RDW-CV), was analyzed by automatic hematology analyzers XE2100 (Sysmex, Japan). Biochemical parameters such as alanine aminotransferase (ALT), total protein (TP), aspartate aminotransferase (AST), albumin (ALB), blood urea nitrogen (BUN), creatinine (CERA), triglyceride (TG), and total cholesterol (T-CHO) were measured by Cobas 8000 Biochemistry Automatic Analyzer (Roche, Germany).

2.4.4. Organs Weight and Histopathological Examinations. At the ending of the experiment, all the rats were euthanized and subjected to necropsy. Pertinent observations on the pathology of each organ were conducted and recorded. Organs such as heart, lung, liver, spleen, kidney, brain, thymus, adrenal gland, testes, and epididymis were weighed before the histopathological tests. Histopathological procedures were conducted according to standard protocols. After trimming at 2-3 mm thickness, formalin-fixed tissues were embedded in paraffin. Moreover, the tissues were cut at sections in $5 \mu \mathrm{m}$ thick and stained with haematoxylin and eosin (H\&E). Microscopic examination was performed on the major organs in all rats at the $1.56 \mathrm{~g} / \mathrm{kg} /$ day dosage treatment 
groups. The findings were compared to parallel sections at $0.39 \mathrm{~g} / \mathrm{kg} /$ day and $0.78 \mathrm{~g} / \mathrm{kg} /$ day dosage group as well as the control group.

2.5. Statistical Analysis. All values were presented using means \pm SD. The differences between the control and dosage groups were statistically evaluated by ANOVA. $P$ value $<0.05$ was considered to be statistically significant. Statistical analyses were conducted by SPSS 24.0 software.

\section{Results}

3.1. Clinical Observations. All the experimental animals survived and appeared healthy during the 90-day period of the study. No treatment-related changes were discovered in daily general observations and clinical examinations.

3.2. Body Weight, Food Consumption, and Food Conversion Efficiency. After the 90-day oral feeding, no statistically significant changes were found in body weights, food consumed, and food conversion efficiency between the treatment and control groups (Table 1).

3.3. Hematology and Biochemical Data. The hematological data were presented in Table 2. No significant changes of hematological parameters were found between the EFE-2 and control group. As for the EFE-1 and EFE-3 group, vital hematological indices including WCV, MCH, MCHC, LY, and MPV were significantly changed $(P<0.05)$ compared to control.

The serum biochemical parameters were summarized in Table 3. In comparison with the control group, no statistically significant differences were discovered in the EFE-1 and EFE-2 group. In comparison to the controls, T-CHO and TG contents of the EFE-3 group had a significant decrease $(P<0.05)$.

3.4. Organ Weights and Pathology. Except for lung and spleen, no significant differences in absolute organ weights were discovered in the EFE groups compared with controls (Table 4). The clinical and pathologic examinations in organs indicated that no significant change was detected between treatment and control groups (data not shown).

\section{Discussion}

Eupatorium japonicum Thunb and Foeniculum vulgare are widely used in many Asian countries and are considered as the major active components in lots of classic traditional Chinese medicine herbal formulas. Previously, the extracts of Eupatorium japonicum Thunb were found to contain the essential oil thymol and several pyrrolizidine alkaloids such as rinderine, amabiline, echinatine, indicine, and viridiflorine (16). Gu et al. (1) reported that ethanol extract of the flowers was one of the suppressors of nitric oxide synthase expression. They conducted a further study of the mechanism of Eupatorium japonicum Thunb for anti-inflammatory effects. Their results provide that it can regulate the Toll/interleukin 1 receptor domain-containing adapter inducing interferon$\beta$-dependent pathways, which lead to the decrease of inflam- matory gene expression (17). Foeniculum vulgare has been extensively utilized in traditional medicine for the treatment of a wide range of diseases. Although the previous studies indicated estragole genotoxicity and hepatocarcinogenicity of Foeniculum vulgare in mice, no DNA damage caused by this medical plant was found in human hepatic cells (18-21). The available scientific study has suggested that it is a critical medical plant for the management of arthritis, cancer, diarrhea, constipation, fever, gastritis, and stomachache (22-30). According to a previous report, Shah and colleagues conducted the toxicity study of the ethanolic extract of Foeniculum vulgare in male and female mice. 3 doses $(0.5,1$, and $3 \mathrm{~g} / \mathrm{kg})$ for acute toxicity and $100 \mathrm{mg} / \mathrm{kg}$ for the 90 -day toxicity dose were used in that research. They concluded that the extracts caused no significant acute or chronic mortality to mice (31). In another study, the juice of the aerial parts of this species was found toxic to rats in a dose of $9.772 \mathrm{mg} / \mathrm{kg} / \mathrm{BW}$. In other words, Foeniculum vulgare leaves juice was suggested slightly toxic to rats (21). Additionally, Rather (32) reported that estragole, one of the major phytoconstituents of Foeniculum vulgare, was associated with the development of malignant tumors in mice. In our recent study, the traditional Chinese herbal medicine compound of Eupatorium japonicum Thunb and Foeniculum vulgare extraction (EFE) has a significant inhibitory effect on benign prostatic hyperplasia. The potential mechanism was suggested that EFE can reduce the expression of bFGF and VEGF protein while enhancing the expression of TGF$\beta$ protein. Moreover, the main components of EFE will be detected to determine the possible mechanism in our further study. It is well known that toxicological screening and safety evaluation on medical plants is essential before therapeutic applications in disorders and diseases. During the last several decades, acute and long-term oral feeding has been advocated as a fundamental test and applied in many safety assessing studies. Therefore, we firstly tested the EFE acute toxicity potency in ICR mice, and the results revealed that the EFE has no toxicity to ICR mice (data not shown). The present study, followed by previous toxicity study, provided evidences of EFE safety using a 90-days oral feeding with dosing up to $1.56 \mathrm{~g} / \mathrm{kg}$ body weight. All toxicity tests in the present study are conducted in compliance with the guidelines of Procedure and Methods of Food Safety Toxicological Assessment (33).

During the course of the experiment, rats in all EFE groups and the control group were all survived in good health. No significant drug-related changes associated with clinical symptoms were found in four groups using ophthalmoscopy and clinical examination.

According to our findings, body weights of the rats in administration groups were significantly lower in week 6 compared to control ones. Nonetheless, no significant difference in the body weight and average feed conversion efficiency were found between the administration groups and control group during the following 90-day period. It is generally accepted that the reduction of body weight gains or losses $10 \%$ more than the mean control value is defined as toxicological significance (34). Therefore, our study 
TABLE 1: Body weight, food consumption, and food conversion efficiency of rats fed with EFE for 90 days.

\begin{tabular}{|c|c|c|c|c|}
\hline & EFE-1 & EFE-2 & EFE-3 & Control \\
\hline Day 0 & $247.30 \pm 11.19^{\mathrm{a}}$ & $246.75 \pm 16.50$ & $238.30 \pm 15.13$ & $242.30 \pm 13.48$ \\
\hline Day 4 & $270.95 \pm 17.14$ & $278.25 \pm 18.35$ & $274.55 \pm 16.76$ & $277.90 \pm 18.10$ \\
\hline Day 8 & $298.35 \pm 16.73$ & $295.80 \pm 15.97$ & $295.10 \pm 18.61$ & $302.35 \pm 15.81$ \\
\hline Day 12 & $311.30 \pm 16.59$ & $317.95 \pm 16.47$ & $314.00 \pm 18.31$ & $317.65 \pm 13.49$ \\
\hline Day 16 & $336.35 \pm 18.99$ & $335.45 \pm 19.85$ & $339.20 \pm 18.88$ & $346.50 \pm 18.07$ \\
\hline Day 20 & $360.20 \pm 20.16$ & $369.70 \pm 20.77$ & $356.85 \pm 20.80$ & $365.45 \pm 16.13$ \\
\hline Day 24 & $376.05 \pm 20.35$ & $383.55 \pm 24.70$ & $370.85 \pm 20.48$ & $377.40 \pm 17.82$ \\
\hline Day 28 & $381.05 \pm 31.27$ & $409.45 \pm 29.01$ & $388.55 \pm 20.42$ & $396.80 \pm 16.49$ \\
\hline Day 32 & $396.65 \pm 34.42$ & $429.10 \pm 28.58$ & $405.50 \pm 22.53$ & $417.05 \pm 21.23$ \\
\hline Day 36 & $410.25 \pm 36.33$ & $450.10 \pm 30.37$ & $424.85 \pm 24.47$ & $437.75 \pm 25.02$ \\
\hline Day 40 & $432.60 \pm 26.74^{*}$ & $458.20 \pm 35.39$ & $445.00 \pm 26.38$ & $460.50 \pm 26.47$ \\
\hline Day 44 & $459.15 \pm 30.61$ & $473.65 \pm 39.06$ & $456.50 \pm 28.38$ & $453.25 \pm 21.02$ \\
\hline Day 48 & $471.95 \pm 32.48$ & $491.50 \pm 38.86$ & $470.95 \pm 30.23$ & $471.85 \pm 24.53$ \\
\hline Day 52 & $482.60 \pm 33.41$ & $499.55 \pm 40.19$ & $477.15 \pm 29.88$ & $482.75 \pm 27.98$ \\
\hline Day 56 & $489.00 \pm 30.45$ & $515.00 \pm 43.12$ & $486.25 \pm 26.44$ & $496.95 \pm 29.29$ \\
\hline Day 60 & $499.05 \pm 33.10$ & $520.75 \pm 43.49$ & $492.05 \pm 27.81$ & $505.70 \pm 30.78$ \\
\hline Day 64 & $509.45 \pm 31.20$ & $530.50 \pm 45.37$ & $503.35 \pm 29.72$ & $511.85 \pm 34.32$ \\
\hline Day 68 & $513.35 \pm 35.32$ & $534.95 \pm 47.58$ & $512.05 \pm 31.34$ & $515.75 \pm 33.98$ \\
\hline Day 72 & $526.30 \pm 38.29$ & $549.50 \pm 48.06$ & $519.80 \pm 33.01$ & $527.90 \pm 35.86$ \\
\hline Day 76 & $526.95 \pm 40.44$ & $549.20 \pm 48.32$ & $521.30 \pm 38.99$ & $533.95 \pm 35.85$ \\
\hline Day 80 & $533.40 \pm 39.71$ & $563.00 \pm 49.26$ & $533.35 \pm 35.14$ & $545.95 \pm 41.58$ \\
\hline Day 84 & $537.50 \pm 39.42$ & $576.60 \pm 45.83$ & $538.40 \pm 32.89$ & $553.45 \pm 40.33$ \\
\hline Day 88 & $542.50 \pm 42.21$ & $571.60 \pm 51.51$ & $539.78 \pm 36.18$ & $557.90 \pm 38.09$ \\
\hline Day 90 & $512.60 \pm 37.70$ & $563.30 \pm 51.29$ & $515.00 \pm 35.48$ & $535.75 \pm 36.28$ \\
\hline Total food consumption ${ }^{\mathrm{b}}$ & $1587.3 \pm 98.6$ & $1923.7 \pm 91.5$ & $1685.6 \pm 86.5$ & $1807.5 \pm 76.4$ \\
\hline Average feed conversion efficiency $(\%)^{\mathfrak{c}}$ & $16.85 \pm 0.98$ & $16.51 \pm 0.82$ & $16.48 \pm 0.69$ & $16.41 \pm 0.77$ \\
\hline
\end{tabular}

${ }^{a}$ Body weight means ( $\mathrm{g} / \mathrm{rat} \pm \mathrm{SD}$ ), food consumed means ( $\mathrm{g} / \mathrm{rat} / \mathrm{day} \pm \mathrm{SD}$, values in parenthesis), and average food conversion efficiency $[($ g weight gain $) /(\mathrm{g}$ feed consumed $) \pm \mathrm{SD}]$ of Sprague-Dawley rats $(n=5 /$ dose $)$ consuming different concentrations of EFE. ${ }^{\mathrm{T}}$ Total food consumption: total food consumed since study initiation. ${ }^{\mathrm{c}}$ Average feed conversion efficiency: total food consumption divided by total body weight gain. Values are significantly different $\left({ }^{*} P<0.05\right)$ as compared with the corresponding control group.

suggests that the EFE administration had no compoundrelated effects on body weight changes in rats.

As for the hematological examination, the mean red blood cell volume (MCV) in the low-dose group was higher than the control one. The MCV increase in the EFE-1 group was not dose-related because the effect was not compounded at the EFE-2 and EFE-3 groups. Additionally, compared with the control group, the mean hemoglobin content $(\mathrm{MCH})$ and mean hemoglobin concentration (MCHC) in the EFE-3 group were found increased by $3.07 \%$ and $1.82 \%$, respectively. A previous study suggested that the increase of $\mathrm{MCV}, \mathrm{MCH}$, as well as $\mathrm{MCHC}$ was correlated with the changes of blood viscosity and RBC deformability (35). However, these statistical differences were not considered adverse or related to the consumption of EFE because these values were comparable between the one EFE group and control group. The lymphocyte count
(LY) and the mean platelet volume (MPV) were decreased by $18.96 \%$ and $3.32 \%$, respectively.

In terms of chemical and biological examination, total cholesterol (T-CHO) and triglyceride (TG) decreased by $20.67 \%$ and $46.15 \%$ in the group of EFE-3 compared with the control one, which may result from the prolonged fasting in the rat before treatment, inducing the excessive binding of triglycerides to proteins. However, the values of TG detected were too low to be statistically analyzed under certain circumstances, which might obscure the investigative process.

Although there were several statistically significant differences between the drug groups and control group, no significant dose-dependent relationship effects were discovered in these abnormal indicators. Consequently, the changes of hematology and biochemical indicators in rats should not be considered as the compound-related effects and was not considered biologically significant. 
TABLE 2: Hematology in rats given EFE for 90 days.

\begin{tabular}{|c|c|c|c|c|}
\hline & EFE-1 & EFE-2 & EFE-3 & Control \\
\hline $\mathrm{WBC}\left(\times 10^{9} / \mathrm{L}\right)$ & $8.42 \pm 3.57^{\mathrm{a}}$ & $9.29 \pm 3.32$ & $6.13 \pm 2.40$ & $9.65 \pm 5.04$ \\
\hline Lymphocyte (\%) & $78.07 \pm 4.59$ & $79.34 \pm 5.82$ & $71.39 \pm 10.11$ & $78.41 \pm 5.80$ \\
\hline Monocyte (\%) & $5.26 \pm 1.51$ & $4.32 \pm 1.37$ & $6.05 \pm 2.84$ & $10.51 \pm 17.47$ \\
\hline Neutrophil (\%) & $14.72 \pm 3.85$ & $14.69 \pm 5.28$ & $20.31 \pm 7.77$ & $14.83 \pm 5.20$ \\
\hline Eosinophil (\%) & $1.93 \pm 0.71$ & $1.64 \pm 0.86$ & $2.24 \pm 1.43$ & $1.64 \pm 0.36$ \\
\hline Basophil (\%) & $0.02 \pm 0.07$ & $0.01 \pm 0.03$ & $0.01 \pm 0.04$ & $0.01 \pm 0.03$ \\
\hline $\mathrm{RBC}\left(\times 10^{12} / \mathrm{L}\right)$ & $8.60 \pm 0.47$ & $8.58 \pm 0.33$ & $8.55 \pm 0.72$ & $8.65 \pm 0.57$ \\
\hline $\mathrm{Hb}(\mathrm{g} / \mathrm{L})$ & $155.67 \pm 7.62$ & $152.90 \pm 5.30$ & $152.88 \pm 10.49$ & $152.10 \pm 6.95$ \\
\hline $\mathrm{HCT}$ & $45.06 \pm 2.26$ & $44.52 \pm 1.40$ & $43.50 \pm 2.90$ & $43.88 \pm 1.86$ \\
\hline $\mathrm{MCV}$ & $52.44 \pm 1.46^{*}$ & $51.92 \pm 1.58$ & $51.63 \pm 0.93$ & $50.85 \pm 1.70$ \\
\hline $\mathrm{MCH}$ & $18.12 \pm 0.59$ & $17.83 \pm 0.53$ & $18.14 \pm 0.19^{*}$ & $17.60 \pm 0.65$ \\
\hline $\mathrm{MCHC}$ & $345.44 \pm 3.17$ & $343.60 \pm 2.46$ & $351.38 \pm 3.70^{*}$ & $346.10 \pm 5.49$ \\
\hline CV RDW & $14.98 \pm 0.41$ & $15.04 \pm 0.51$ & $15.26 \pm 0.44$ & $15.33 \pm 0.48$ \\
\hline LY & $6.68 \pm 3.08$ & $7.46 \pm 2.94$ & $4.53 \pm 2.21^{*}$ & $9.50 \pm 5.59$ \\
\hline $\mathrm{MO}$ & $0.46 \pm 0.27$ & $0.43 \pm 0.25$ & $0.36 \pm 0.22$ & $0.49 \pm 0.24$ \\
\hline $\mathrm{NE}$ & $1.14 \pm 0.32$ & $1.26 \pm 0.35$ & $1.14 \pm 0.30$ & $1.33 \pm 0.52$ \\
\hline $\mathrm{EO}$ & $0.15 \pm 0.05$ & $0.14 \pm 0.05$ & $0.11 \pm 0.05$ & $0.16 \pm 0.09$ \\
\hline $\mathrm{LT}$ & $869.00 \pm 79.52$ & $883.10 \pm 71.83$ & $884.88 \pm 128.70$ & $954.60 \pm 117.13$ \\
\hline MPV & $6.46 \pm 0.21$ & $6.49 \pm 0.30$ & $6.41 \pm 0.22^{*}$ & $6.63 \pm 0.19$ \\
\hline
\end{tabular}

${ }^{a}$ Values are means \pm standard deviations. Values are significantly different $\left({ }^{*} P<0.05\right)$ as compared with the corresponding control group.

TABLE 3: Serum biochemistry in rats given EFE for 90 days.

\begin{tabular}{lcccc}
\hline & EFE-1 & EFE-2 & EFE-3 & Control \\
\hline TP $(\mathrm{g} / \mathrm{L})$ & $56.28 \pm 2.68^{\mathrm{a}}$ & $53.29 \pm 1.64$ & $57.06 \pm 1.70$ & $55.15 \pm 3.51$ \\
$\mathrm{ALB}(\mathrm{g} / \mathrm{L})$ & $37.91 \pm 1.99$ & $35.31 \pm 1.63$ & $39.09 \pm 1.51$ & $37.13 \pm 2.30$ \\
$\mathrm{ALT}(\mathrm{U} / \mathrm{L})$ & $33.56 \pm 7.04$ & $34.60 \pm 7.47$ & $29.00 \pm 6.61$ & $30.90 \pm 6.24$ \\
$\mathrm{AST}(\mathrm{U} / \mathrm{L})$ & $101.44 \pm 23.48$ & $85.40 \pm 14.78$ & $110.63 \pm 35.36$ & $87.20 \pm 11.77$ \\
$\mathrm{BUN}(\mathrm{mmol} / \mathrm{L})$ & $6.52 \pm 1.00$ & $4.90 \pm 0.64$ & $4.89 \pm 0.71$ & $5.49 \pm 2.07$ \\
CERA $(\mu \mathrm{mol} / \mathrm{L})$ & $45.22 \pm 5.89$ & $36.50 \pm 6.28$ & $39.38 \pm 10.20$ & $41.10 \pm 12.13$ \\
T-CHO $(\mathrm{mmol} / \mathrm{L})$ & $1.68 \pm 0.41$ & $1.57 \pm 0.25$ & $1.42 \pm 0.30^{*}$ & $1.79 \pm 0.29$ \\
TG $(\mathrm{mmol} / \mathrm{L})$ & $0.81 \pm 0.27$ & $1.25 \pm 0.47$ & $0.42 \pm 0.20^{*}$ & $0.78 \pm 0.39$ \\
\hline
\end{tabular}

${ }^{a}$ Values are means \pm standard deviations. Values are significantly different $\left({ }^{*} P<0.05\right)$ as compared with the corresponding control group.

In the analysis of organ weight and histopathological, though significant differences in absolute weights were discovered in lung and spleen, no obvious lesions were found in further histopathological examination and these changes could be considered to be incidental.

Overall, compared with the control group, we discovered a decrease in the body weight, T-CHO, as well as TG, and an increase in the MCV and MCH along with MCHC in the EFE group. However, these alterations were not dose-related, and no significant correlations were found with the EFE. We attribute this phenomenon to some extraneous factors as well as biological variations arising from inter- and intra-animal components. In addition, other physiological factors including age, sex, restraint, diet, and circadian may also have the effects on the overall variation. The results of our research confirm that there are no adverse effects due to the administration of EFE in traditional medicine.

\section{Conclusion}

To the best of our knowledge, this is the first study on the safety assessment of EFE. In the present study, the results suggest that EFE on prolonged administration may cause a slight change in body weight and hematological examination 
TABLE 4: Organ weights in rats given EFE for 90 days.

\begin{tabular}{|c|c|c|c|c|}
\hline Item & EFE-1 & EFE-2 & EFE-3 & Control \\
\hline \multicolumn{5}{|c|}{ Absolute organ weight (g) } \\
\hline Heart & $1.383 \pm 0.169^{\mathrm{a}}$ & $1.418 \pm 0.155$ & $1.309 \pm 0.095$ & $1.383 \pm 0.097$ \\
\hline Lung & $1.723 \pm 0.133$ & $1.826 \pm 0.188$ & $1.573 \pm 0.057^{*}$ & $1.690 \pm 0.116$ \\
\hline Liver & $14.684 \pm 1.676$ & $16.280 \pm 2.129$ & $13.423 \pm 0.980$ & $13.634 \pm 1.385$ \\
\hline Spleen & $0.863 \pm 0.153$ & $0.953 \pm 0.187^{*}$ & $0.734 \pm 0.120$ & $0.798 \pm 0.071$ \\
\hline Kidney & $3.199 \pm 0.257$ & $3.295 \pm 0.362$ & $3.139 \pm 0.355$ & $3.036 \pm 0.196$ \\
\hline Brain & $2.137 \pm 0.064$ & $2.128 \pm 0.116$ & $2.045 \pm 0.149$ & $2.059 \pm 0.138$ \\
\hline Thymus & $0.369 \pm 0.094$ & $0.362 \pm 0.068$ & $0.396 \pm 0.093$ & $0.340 \pm 0.063$ \\
\hline Adrenal gland & $0.051 \pm 0.017$ & $0.052 \pm 0.009$ & $0.046 \pm 0.013$ & $0.055 \pm 0.013$ \\
\hline Testes & $3.712 \pm 0.212$ & $3.984 \pm 1.014$ & $3.393 \pm 0.322$ & $3.507 \pm 0.197$ \\
\hline Epididymis & $1.297 \pm 0.098$ & $1.308 \pm 0.306$ & $1.180 \pm 0.149$ & $1.135 \pm 0.274$ \\
\hline \multicolumn{5}{|c|}{ Relative organ weight (\%) } \\
\hline Heart & $0.25 \pm 0.07$ & $0.27 \pm 0.03$ & $0.24 \pm 0.05$ & $0.25 \pm 0.03$ \\
\hline Lung & $0.35 \pm 0.05$ & $0.32 \pm 0.02$ & $0.29 \pm 0.06$ & $0.31 \pm 0.05$ \\
\hline Liver & $2.86 \pm 0.21$ & $2.79 \pm 0.28$ & $2.63 \pm 0.19$ & $2.59 \pm 0.26$ \\
\hline Spleen & $0.19 \pm 0.08$ & $0.22 \pm 0.03$ & $0.17 \pm 0.04$ & $0.17 \pm 0.08$ \\
\hline Kidney & $0.63 \pm 0.07$ & $0.67 \pm 0.09$ & $0.58 \pm 0.03$ & $0.59 \pm 0.04$ \\
\hline Brain & $0.47 \pm 0.05$ & $0.41 \pm 0.03$ & $0.39 \pm 0.06$ & $0.44 \pm 0.05$ \\
\hline Thymus & $0.07 \pm 0.008$ & $0.06 \pm 0.005$ & $0.06 \pm 0.007$ & $0.07 \pm 0.005$ \\
\hline Adrenal gland & $0.009 \pm 0.0008$ & $0.010 \pm 0.0009$ & $0.009 \pm 0.0005$ & $0.009 \pm 0.0006$ \\
\hline Testes & $0.77 \pm 0.08$ & $0.69 \pm 0.04$ & $0.76 \pm 0.05$ & $0.73 \pm 0.04$ \\
\hline Epididymis & $0.28 \pm 0.06$ & $0.26 \pm 0.02$ & $0.25 \pm 0.04$ & $0.26 \pm 0.07$ \\
\hline
\end{tabular}

${ }^{a}$ Values are means \pm standard deviations. Values are significantly different $\left({ }^{*} P<0.05\right)$ as compared with the corresponding control group.

but could harbor no significant toxicological effect. Therefore, our study provides some evidence on the safety of the ethanol extract of Eupatorium japonicum Thunb and Foeniculum vulgare for potential clinical application. In addition, further studies of EFE are still necessary to assess its oral safety in patients.

\section{Data Availability}

All data generated or analyzed during this study are included in this article.

\section{Ethical Approval}

All procedures conducted in this study were in compliance with the Declaration of Helsinki and obtained the appropriate approval by the committee of Soochow University of Science and Technology.

\section{Conflicts of Interest}

The authors declare that there are no conflicts of interest.

\section{Authors' Contributions}

Guangcheng Dai and Chenglu Wang contributed to the work equally and should be regarded as co-first authors.

\section{Acknowledgments}

This work was funded by the Suzhou Science and Technology Development Plan Project (No. SYS201720) and the Pre-Research Fund Project for NSFC of the Second Affiliated Hospital of Soochow University (No. sdfergj1707).

\section{References}

[1] G.-J. Gu, S.-H. Eom, H.-J. Shin et al., "Japanese bog orchid (Eupatorium japonicum) extract suppresses expression of inducible nitric oxide synthase and cyclooxygenase-2 induced by toll-like receptor agonists," Food Science and Biotechnology, vol. 22, no. 3, pp. 811-815, 2013.

[2] J.-I. Shin, Y.-J. Jeon, S. Lee et al., "Apoptotic and antiinflammatory effects of Eupatorium japonicum Thunb. In rheumatoid arthritis fibroblast-like synoviocytes," BioMed Research International, vol. 2018, Article ID 1383697, 11 pages, 2018.

[3] Y. Zhang, Y. Wang, M. Li et al., "Traditional uses, bioactive constituents, biological functions, and safety properties of 
Oviductus ranae as functional foods in China," Oxidative Medicine and Cellular Longevity, vol. 2019, Article ID 4739450, 24 pages, 2019.

[4] B. Muckensturm, D. Foechterlen, J.-P. Reduron, P. Danton, and M. Hildenbrand, "Phytochemical and chemotaxonomic studies of Foeniculum vulgare," Biochemical Systematics and Ecology, vol. 25, no. 4, pp. 353-358, 1997.

[5] A. Dua, G. Garg, and R. Mahajan, "Polyphenols, flavonoids and antimicrobial properties of methanolic extract of fennel (Foeniculum vulgare Miller)," European Journal of Experimental Biology, vol. 3, pp. 203-208, 2013.

[6] I. Erdogan Orhan, B. Özçelik, M. Kartal, and Y. Kan, “Antimicrobial and antiviral effects of essential oils from selected Umbelliferae and Labiatae plants and individual essential oil components," Turkish Journal of Biology, vol. 36, pp. 239246, 2012.

[7] R. Manonmani and V. Mohideen Abdul Khadir, "Antibacterial screening on Foeniculum vulgare Mill," International Journal of Pharma and Bio Sciences, vol. 2, pp. 390-394, 2011.

[8] N. El-Soud, N. El-Laithy, G. El-Saeed et al., "Antidiabetic activities of Foeniculum vulgare Mill. essential oil in streptozotocin-induced diabetic rats," Macedonian Journal of Medical Sciences, vol. 4, pp. 139-146, 2011.

[9] S. Minz, "In-vitro cytoprotection activity of Foeniculum vulgare and Helicteres isora in cultured human blood lymphocytes and antitumour activity against B16F10 melanoma cell line," Research Journal of Pharmacy and Technology, vol. 1, no. 4 , pp. 450-452, 2008.

[10] H. Özbek, S. Ugras, H. Dülger et al., "Hepatoprotective effect of Foeniculum vulgare essential oil," Fitoterapia, vol. 74, no. 3, pp. 317-319, 2003.

[11] M. Oktay, I. Gülçin, and Ö. İ. Küfrevioğlu, "Determination of in vitro antioxidant activity of fennel (Foeniculum vulgare) seed extracts," LWT - Food Science and Technology, vol. 36, no. 2, pp. 263-271, 2003.

[12] T. Malini, G. Vanithakumari, N. Megala, S. Anusya, K. Devi, and V. Elango, "Effect of Foeniculum vulgare Mill. seed extract on the genital organs of male and female rats," Indian Journal of Physiology and Pharmacology, vol. 29, no. 1, pp. 21-26, 1985.

[13] S. Koppula and H. Kumar, "Foeniculum vulgare Mill (Umbelliferae) attenuates stress and improves memory in Wister rats," Tropical Journal of Pharmaceutical Research, vol. 12, pp. 553558, 2013.

[14] W. Tang, G. C. Dai, B. X. Xue, Y. X. Shan, and W. F. Zhang, "The inhibitory effect of eupatorium japonicum thunb and foeniculum vulgare extract on prostatic hyperplasia in rats," Journal of Medical Postgraduates, vol. 27, pp. 1266-1268, 2014.

[15] L. Lu, Y. Fan, W. Yao et al., "Safety assessment of the fermented Phylloporia ribis (Lonicera japonica Thunb.) mycelia by oral acute toxicity study in mice and 90-day feeding study in rats," Food and Chemical Toxicology, vol. 69, pp. 18-24, 2014.

[16] J. A. Edgar, H. J. Lin, C. R. Kumana, and M. M. T. Ng, "Pyrrolizidine alkaloid composition of three Chinese medicinal Herbs,Eupatorium cannabinum, E. japonicum and Crotalaria assamica," The American Journal of Chinese Medicine, vol. 20, no. 03n04, pp. 281-288, 2012.

[17] G.-J. Gu, S.-I. Ahn, S. J. Lim et al., "Eupatorium japonicum extract regulates inflammation through suppression of the TRIF-dependent signaling pathway of toll-like receptors,"
Food Science and Biotechnology, vol. 23, no. 2, pp. 587-592, 2014.

[18] M. Ahmad, M. A. Butt, G. Zhang, S. Sultana, A. Tariq, and M. Zafar, "Bergenia ciliata: a comprehensive review of its traditional uses, phytochemistry, pharmacology and safety," Biomedicine \& Pharmacotherapy, vol. 97, pp. 708-721, 2018.

[19] S. Levorato, L. Dominici, C. Fatigoni et al., "In vitro toxicity evaluation of estragole-containing preparations derived from Foeniculum vulgare Mill. (fennel) on HepG2 cells," Food and Chemical Toxicology, vol. 111, pp. 616-622, 2018.

[20] M. Y. Chan, X. L. Zhao, and C. W. Ogle, "A comparative study on the hepatic toxicity and metabolism of Crotalaria assamica and Eupatorium species," The American Journal of Chinese Medicine, vol. 17, pp. 165-170, 2012.

[21] F. A. Al-Hizab, Y. A. Hussein, M. M. Hasseeb, S. E. M. Barakat, and M. S. Moqbel, "Toxico-pathological studies of \&lt;i\&gt;Foeniculum vulgare\&lt;/i\&gt; Plant in Mice," Open Journal of Pathology, vol. 8, no. 4, pp. 123-131, 2018.

[22] M. del Carmen Juárez-Vázquez, C. Carranza-Álvarez, A. J. Alonso-Castro et al., "Ethnobotany of medicinal plants used in Xalpatlahuac, Guerrero, Mexico," Journal of ethnopharmacology, vol. 148, no. 2, pp. 521-527, 2013.

[23] R. Sharma, R. Manhas, and R. Magotra, "Ethnoveterinary remedies of diseases among milk yielding animals in Kathua, Jammu and Kashmir, India," Journal of Ethnopharmacology, vol. 141, no. 1, pp. 265-272, 2012.

[24] S. Jarić, M. Mitrović, L. Djurdjević et al., "Phytotherapy in medieval Serbian medicine according to the pharmacological manuscripts of the Chilandar Medical Codex (15-16th centuries)," Journal of Ethnopharmacology, vol. 137, no. 1, pp. 601-619, 2011.

[25] F. Lewu and A. Afolayan, "Ethnomedicine in South Africa: the role of weedy species," African Journal of Biotechnology, vol. 8, pp. 929-934, 2009.

[26] L. Cornara, A. La Rocca, S. Marsili, and M. Mariotti, "Traditional uses of plants in the eastern Riviera (Liguria, Italy)," Journal of Ethnopharmacology, vol. 125, no. 1, pp. 16-30, 2009.

[27] M. Kumar, Y. Paul, and V. K. Anand, "An ethnobotanical study of medicinal plants used by the locals in Kishtwar, Jammu and Kashmir, India," Ethnobotanical Leaflets, vol. 13, no. 10, p. 5, 2009.

[28] V. Tene, O. Malagon, P. Vita-Finzi, G. Vidari, C. Armijos, and T. Zaragoza, "An ethnobotanical survey of medicinal plants used in Loja and Zamora- Chinchipe, Ecuador," Journal of ethnopharmacology, vol. 111, no. 1, pp. 63-81, 2007.

[29] A. Ghorbani, "Studies on pharmaceutical ethnobotany in the region of Turkmen Sahra, north of Iran (part 1): general results," Journal of Ethnopharmacology, vol. 102, no. 1, pp. 58-68, 2005.

[30] M. M. Al-Harbi, S. Qureshi, M. Raza, M. Ahmed, A. Giangreco, and A. Shah, "Influence of anethole treatment on the tumour induced by Ehrlich ascites carcinoma cells in paw of Swiss albino mice," European Journal of Cancer Prevention, vol. 4, no. 4, pp. 307-318, 1995.

[31] A. H. Shah, S. Qureshi, and A. M. Ageel, "Toxicity studies in mice of ethanol extracts of Foeniculum vulgare fruit and Ruta chalepensis aerial parts," Journal of Ethnopharmacology, vol. 34, no. 2-3, pp. 167-172, 1991.

[32] M. A. Rather, B. A. Dar, S. N. Sofi, B. A. Bhat, and M. A. Qurishi, "Foeniculum vulgare: a comprehensive review of its 
traditional use, phytochemistry, pharmacology, and safety," Arabian Journal of Chemistry, vol. 9, pp. S1574-S1583, 2016.

[33] China's Ministry of Health, Procedure and methods of food safety toxicological assessment, National Health Commission of the People's Republic of China, 2003, GB15193-2003.

[34] A. Hayes, Principles and methods of, toxicology, Raven Press, New York, NY, USA, 5th edition, 2008.

[35] G. F. von Tempelhoff, O. Schelkunov, A. Demirhan et al., "Correlation between blood rheological properties and red blood cell indices(MCH, MCV, MCHC) in healthy women," Clinical Hemorheology and Microcirculation, vol. 62, no. 1, pp. 45-54, 2016. 